See Article page 389.

\section{Commentary: To bleed or not to bleed, that is the question- Anticoagulation in surgical patients on prolonged extracorporeal membrane oxygenation}

\author{
Thomas Schweiger, $\mathrm{MD}, \mathrm{PhD}$, and \\ Konrad Hoetzenecker, MD, PhD
}

Extracorporeal membrane oxygenation (ECMO) can tremendously facilitate complex airway surgery or surgery in patients with limited cardiopulmonary reserve. ${ }^{1-3}$ Hawkins and colleagues ${ }^{4}$ report a complex case of a 53year-old female patient with viral pneumonia, an iatrogenic tracheal tear, and severe soft-tissue emphysema. A femorofemoral venovenous ECMO was established to initially stabilize the patient and support the surgical repair. Subsequently, the ECMO was prolonged for 2 weeks to reduce ventilation pressures and thus facilitate the healing of the airway. This case report is an excellent example of how ECMO can be used to provide a definitive surgical repair to a critically ill patient in a controlled and stable setting with an otherwise fatal course. However, it has to be mentioned that 2 ECMO-related adverse events complicated the postoperative course of the patient: bleeding at the surgical site requiring revision surgery and deep-vein thrombosis treated by insertion of a vena cava filter.

During the last decade, ECMO has evolved to become a fundamental part of cardiothoracic surgery, with steadily growing numbers of annual ECMO runs worldwide. ${ }^{5}$ Despite the obvious, often life-saving advantages of

\footnotetext{
From the Department of Thoracic Surgery, Medical University of Vienna, Vienna, Austria.

Disclosures: The authors reported no conflicts of interest.

The Journal policy requires editors and reviewers to disclose conflicts of interest and to decline handling or reviewing manuscripts for which they may have a conflict of interest. The editors and reviewers of this article have no conflicts of interest.

Received for publication July 27, 2020; revisions received July 27, 2020; accepted for publication July 31, 2020; available ahead of print Aug 12, 2020.

Address for reprints: Konrad Hoetzenecker, MD, PhD, Department of Thoracic Surgery, Medical University Vienna, Waehringer Guertel 18-20, 1090 Vienna, Austria (E-mail: konrad.hoetzenecker@meduniwien.ac.at).

JTCVS Techniques 2020;4:393-4

2666-2507

Copyright (C) 2020 The Authors. Published by Elsevier Inc. on behalf of The American Association for Thoracic Surgery. This is an open access article under the CC BY-NCND license (http://creativecommons.org/licenses/by-nc-nd/4.0/).

https://doi.org/10.1016/j.xjtc.2020.07.033
}

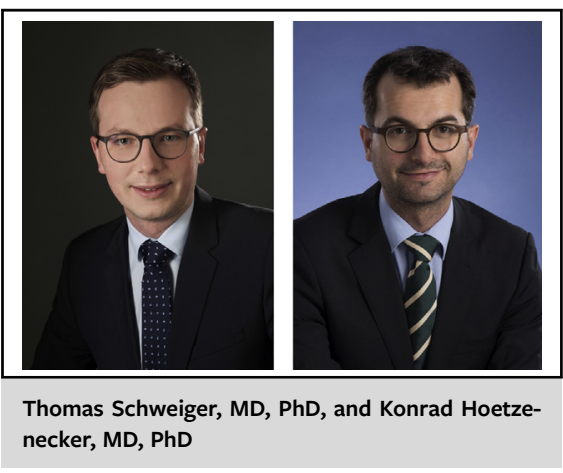

CENTRAL MESSAGE

In patients on prolonged postoperative ECMO support, an individualized anticoagulation strategy has to be established, balancing between the risk for bleeding and thromboembolic complications.

ECMO, a word of caution is warranted. The incidence of thromboembolic complications in patients on venovenous ECMO is described as high as $53 \%$ and relevant bleeding occurs in up to $16 \%{ }^{6}$ These numbers illustrate the dilemma of anticoagulation in surgical patients requiring ECMO, especially if it has to be extended postoperatively.

In our experience, during the early postoperative course, the risk of bleeding by far exceeds possible thromboembolic events in patients on ECMO. Thus, anticoagulation can be kept at a minimum or can even be completely omitted for up to 48 hours if heparin-coated circuits are used and blood flow is maintained above $2 \mathrm{~L} / \mathrm{min}$. Anticoagulation can be gradually increased after sufficient hemostasis has occurred on the surgical site. Such a situation-dependent anticoagulation goes beyond normograms and activated clotting time target levels but requires a regular assessment of the drain fluid by the surgeon and a complete laboratory panel of coagulation, including thromboelastometry. We have previously shown that with such a tailored anticoagulation strategy even in complex lung transplantation, a postoperative prolongation of ECMO for several days is feasible and safe. Despite the considerably larger surgical trauma (compared with a single thoracotomy to repair a tracheal laceration), uncontrolled bleeding was generally not seen.

In summary, ECMO can be a lifesaving tool but comes along with a certain risk of complications and pitfalls, especially in patients receiving complex surgical procedures. As 
general guidelines are not applicable, an individualized anticoagulation management should be defined in every patient and monitored closely. Considering the required experience, surgical procedures with prolonged ECMO support should only be performed at specialized centers.

\section{References}

1. Hoetzenecker K, Klepetko W, Keshavjee S, Cypel M. Extracorporeal support in airway surgery. J Thorac Dis. 2017;9:2108-17.

2. Lang G, Ghanim B, Hötzenecker K, Klikovits T, Matilla JR, Aigner C, et al. Extracorporeal membrane oxygenation support for complex tracheo-bronchial procedures. Eur J Cardiothorac Surg. 2015;47:250-5; discussion 256.
3. Redwan B, Ziegeler S, Freermann S, Nique L, Semik M, Lavae-Mokhtari M, et al. Intraoperative veno-venous extracorporeal lung support in thoracic surgery: a single-centre experience. Interact Cardiovasc Thorac Surg. 2015;21:766-72.

4. Hawkins R, Thiele E, Martin L. Extracorporeal membrane oxygenation for management of iatrogenic distal tracheal tear. J Thorac Cardiovasc Surg Tech. 2020;4: 389-91.

5. ELSO Registry Report. Ann Arbor, MI; 2020. Available at: https://www.elso.org/ Registry/Statistics/InternationalSummary.aspx. Accessed July 27, 2020.

6. Sklar MC, Sy E, Lequier L, Fan E, Kanji HD. Anticoagulation practices during venovenous extracorporeal membrane oxygenation for respiratory failure. A systematic review. Ann Am Thorac Soc. 2016;13:2242-50.

7. Hoetzenecker K, Benazzo A, Stork T, Sinn K, Schwarz S, Schweiger T, et al. Bilateral lung transplantation on intraoperative extracorporeal membrane oxygenator: an observational study. J Thorac Cardiovasc Surg. 2020;160:320-7.e1. 